\title{
Analysis of Teaching Methods Innovation of Legal Professions of Higher Vocational Education
}

\author{
Xu Hui; Wan Yinghua; Feng Xiaoxia \\ Institute of Political Science and Law, Xingtai University, Xingtai Hebei 054001
}

\begin{abstract}
With the needs of economic and social development, the legal system of China has been constantly improved. As a result, our country is in increasingly urgent demand for legal professionals. Legal professions of higher vocational colleges are responsible for the training of a variety of application-oriented legal talents for our country, which plays a very important role for the construction of the legal system. However, at present, there are some disadvantages in teaching methods of higher vocational legal professions, such as the imitation of general education while lack of vocational characteristics, the rigid and single teaching methods, and theory divorced from reality. The paper will start from these drawbacks, and will propose such appropriate solutions as the introduction of teaching method of case study, the implementation of "Clinic-style" practical teaching, and the conduction of "Law-article" teaching method, in the hope of offering some help to the development of higher vocational legal professions and cultivating truly practical legal talents with professional capacity, able to take up the mission of the law, and able to make a significant contribution to the legal system construction of the country, in cooperation with this wide range of vocational legal education models.
\end{abstract}

Keywords: legal profession of higher vocational colleges; disadvantages of teaching methods; solutions.

With the continuous development of economy and society, trade activities are becoming increasingly frequent, meanwhile, the socialist legal system has been constantly improved, as a result, social development and progress is in increasingly urgent demand for legal talent. Legal professions of higher vocational colleges are responsible for the training of various applicationoriented legal talents for our country, which plays a very important role for the construction of legal system of our country. In such a situation, the education of higher vocational legal professions face more severe challenges, the work in various aspects still requires constant innovation. In recent years, with the national attention, the legal professions of higher vocational education has made considerable progress and development, however, it is in need to see that there are still some drawbacks in teaching philosophy, educational philosophy, educational methods and training methods, which cannot adapt to the new situation, and need to be solved during the constant development process. Starting from the shortcomings of the teaching methods of legal professions of our country, this thesis will propose corresponding solutions, with the purpose to provide some help to the development of higher vocational legal professions.

\section{Shortcomings of the Teaching Methods of Higher Vocational Legal Professions of Our Country}

\subsection{Imitation of General Education and Lack of}

\section{Vocational Characteristics}

The legal profession vocational colleges include the Administrative Cadre Institute of Politics and Law, Cadre School of Public Security, the Higher Vocational Colleges, Adult Institutions and the Higher Vocational Colleges of Judicial Police. The majors of these institutions generally are legal assistants, judiciary secretaries, prison management, administration of justice, public security administration, economic law, network security, and foreign-related economic and legal professions and so on. ISCO chaotic phenomenon has come into being since the higher vocational legal professions are not the same as the legal education, the development of China's vocational legal education is not very mature, the professional settings are not scientific, and entry requirements to students are relatively low.

Furthermore, the unclear training objectives lead to the great pressure of current vocational legal professions, especially the pressure on teaching methods and models. Many vocational law schools follow the teaching model ordinary institutions of higher education in that they focus on students' theory learning abilities, while ignore the cultivation and improvement of their practical skills. Thus, in the actual teaching process, the well established teaching tasks will not be able to be completed, and the trained personnel cannot meet the needs of society. Higher vocational legal professions has always followed a "hard tack" teaching model, and the different professional courses are refined and then re-learned, thus leading to blur on their teaching methods, and the 
specialty and training purposes cannot be reflected.

\subsection{Rigid and Single Teaching Methods}

Most vocational colleges of legal professions are still mired in the traditional teaching methods and models, which are not able to generate more interaction between teachers and students, such as class discussion and exchange after class. Most teachers just complete the teaching objectives in accordance with the established curriculum, and students are learning about the notes according to the teacher or textbook based on the rote manner. In addition, although some institutions pay attention to the training of students' practical ability, they blindly emphasized practice, and ignore students' theoretical study, therefore, neither is a good ways to complete the teaching purposes of vocational legal professions, and not to say the training of outstanding legal talent for the country.

\subsection{Theory Divorced from Reality}

In some vocational teaching of the legal profession, there is a serious phenomenon of theory being divorced from reality. Many teachers focus only on legal provisions and principles, ignoring the most important training of practical skills. Furthermore, many teachers themselves lack practical experience, so they will confuse the specific operating procedures when teaching. For instance, the teacher who teaches procedural law may simply does not know how to initiate the procedure; the professor of financial law does not understand the procedure and operation mode of finance; the teacher of securities has no idea of how to make and use notes, the instructor of company law lack the knowledge of the specific structure and establishment of the company. The teaching methods of theory being divorced from reality as the above are difficult for students to trust and accept.

In addition, those traditional teaching methods are more tedious, which lack the interaction between teachers and students. Students may think that what teachers teach is correct, and therefore they remember the rote knowledge, with the purpose to ensure the smooth pass of the exam, regardless of the correctness of their teacher's points of view. This passive way of knowledge acceptance make the students unable to form their own views, nor will they ask questions or think about the teaching content, which will directly affect their ability to think independently and to solve practical problems. So after graduation, they cannot meet the needs of the community, and cannot cope with the intricacies of the legal relationship.

\section{Teaching Methods Suitable for Legal Professions of Vocational Education}

\subsection{Introduction of Teaching Method of Case Study}

The implementation of the case teaching method, is not only a good means for teachers, but also essential for students and teaching material. In order to further facilitate the teaching of law, teachers need to establish the case base in advance, that is to say, teachers need to write a book about the cases for students in advance, which is quite useful not only for the establishment of the case library, but also save the teachers' class time. Meanwhile, EDI should be promoted and applied, as it is more difficult for teachers to explain through the regular classroom cases. Moreover, according to the traditional teaching, the teacher will copy the case on the blackboard, however, the general case is relatively long, and the copy text on the blackboard are not easy for students to remember and understand. Therefore, the use of multimedia and electronic courseware for teaching should be introduced, which can not only help teachers save class time, but also allows the teacher to get ready for the case in class. Teachers can follow the requirements of the curriculum, collect data according to teaching content of each chapter, and edit and rewrite the cases in demand. In the classroom, the teacher can explain to students on the cases distributed before the class, and organize students to do class discussions.

Classroom discussion is the main way of case teaching, it is also the center for case teaching, where it needs teachers and students to actively participate in. In this panel of discussion, the teachers generally act as the directors, who are mainly responsible for command and planning; while as the major actors, the students must actively get involved in, ask questions and analyze these cases. In general, students' participation and the knowledge they have learned is the key to the whole case teaching. The main concrete steps for class discussion are as follows.

First, the teacher explains the content involved in cases, present the cases to the students through the multimedia and organizing students to conduct class discussions. This form of discussions can be in either group or class, it can be an adversarial discussion of the both masters, or the teacher can arrange it as after-school homework for students to discuss after class. Second, after the case discussion, the teacher should guide students to write case analysis report. Case Analysis Report can be considered as the students' studies and experiences of the case analysis, which can better consolidate the results discussed in class, improve students' ability of summary, better improve students' logic skills of case analysis, and further grasp the ideas and methods of case analysis. Third, when guiding students to write the analysis report, be sure to tell them the differences among the analysis report, the discussion records and the ideological summary. Analysis reports need not have a fixed format, but its theme must be clear, must reflect the main issues of the case in the content, reflect students' own points of view, and reflect the laws and regulations used, reference materials, and experience feelings. Finally, the teacher should mark the analysis reports handed in by the students, and evaluate on students' learning ability and performance according to their analysis reports.

\subsection{Implementation of the "Clinic-style" Practical Teaching}

The so-called "clinic-style" teaching requires the establishment of legal clinics, where the related legal advice is offered, and requires the insurance of the daily 
operation of the legal clinics. Only properly functioning legal clinic is able to provide places and basic conditions for undertaking a variety of legal practice activities. In the practice of the legal clinics, it is possible for the students to learn the knowledge and skills that cannot be learnt in the classroom. The location of legal clinics should be not far from the college, which is mainly for the convenience of the daily operation of the legal clinic management, and for the convenience of the access of students and teachers. In addition, the convenience of those who will consult for help should be take into consideration, once legal clinics set in more remote locations, or in place that is difficult to find, it will cause the callers inconvenience, and will affect the conduction of practice teaching of legal clinics. What is essential for legal clinic is "quasi-lawyer" candidate selection, and as to how to select the students to practice in clinic, the author believes it should be conducted from the following aspects.

Firstly, the number of people joining in legal clinics should be limited. This is mainly because the number of law teachers of vocational colleges is relatively small, and once put into practice, the teachers of legal clinics will be asked to spent a lot of time and energy to teach. Therefore, the limitation of students' number is necessary. It is better for a teacher to guide 7-10 students, preferably not more than 10 people. Moreover, the limitation of the number can spare enough time for the teacher to guide students in handling cases, and can guarantee the quality of the case handled to a large extent.

Secondly, a strict selection process should be set for the choice of the students carrying out the work of the legal clinic. Generally speaking, there should be such methods as written exam, interview assessment, and the teachers' recommendation for students to conduct. The set of the appropriate assessment system for students when joining the legal clinic is mainly to ensure the smooth progress of "clinic-style" teaching practice.

Thirdly, certain entry criteria should be set. In the selection of students, the learning background of the students must be first assessed. In general, students who are familiar with the degree law and substantive law should have priority, because for those callers, this is the real work needed in legal practice. In addition, for students in the sophomore and junior years of vocational legal profession, they generally have completed the learning of degree law and substantive law, so it is better to pick and choose among them. Besides, during the selection process, such factors should also be taken into account as the student's own interpersonal skills, coordination skills, personal willpower and overall quality, was elected to the of its legal clinic instructor. According to these conditions, the "clinic-style" teaching can be smoothly carried out.

\subsection{Implementation of the "Law-article" Teaching Method}

First, the conduction of "law-article" teaching method requires students to read the articles of the law seriously and carefully. This method is not the teacher reading for the students, but the students read carefully in class by themselves.

Second, the teacher should answer the students' questions and offer the guidance. After the careful reading, students may find the points they do not understand, which the teacher will need to record and respond.

Third, students need to interpret the statute. In this process, students are required to focus on and the law and memorize the main point and the central terns of the law articles. This process can be considered as the most fundamental and important aspects for students to master the articles and the corresponding system.

Fourth, for the students, they may often overlook some important words in the interpretation process, so as a teacher, he or she must guide and help the students to catch the key words, to understand the meaning of those words. Only when students learn to find, understand and grasp the crucial words, it is possible for them to understand, apply and operate the knowledge of the law. When students learn to master the key words, the teacher should explain to the students based on the legal system and the issues unfound during the reading. In this process, the teacher is not only required to explain the law, but also required to explain the basic concept, the basic theory and the basic knowledge of the relevant legal system.

Fifth, teachers need to explain some other provisions involved to a certain extent. These relevant provisions do not need to be explained one by one, but the teacher must instruct and remind the students, which will improve the students' analysis ability of specific problems, enable students to develop multiple case studies habit in a timely case analysis, and greatly help to expand their knowledge.

Sixth, to the problems which have not yet given a clear answer in the provision and the issues waiting for solutions, teachers and students should discuss together. For this discussion, it must be built on the premise that these issues are in the sense of discussion.

Finally, in the case of a conditional instruction, it is necessary for the teachers to teach the provisions in accordance with their own ideas, to explain the actual situation, and to comprehensively explain the relevant knowledge points, with the purpose to ensure that students can completely and systematically learn and absorb these knowledge points.

\section{Conclusion}

In short, despite a late start of the vocational education in China, with the needs of social development, it has been in a trend of rapid development, and account for a large proportion in the distribution of higher education. The main educational goal of higher legal profession is to train more outstanding full-time legal staff, who are not only required to have a good theoretical knowledge of law, but also required to be familiar with China's major laws and regulations, and also required to have a very strong adaptability and innovation capability in business. In addition, the main purpose of the training for legal professionals of vocational education lies in the supplement of the legal department staff in our country, which requires that they have the ability to face the 
grassroots work and are the practical legal professionals in line with the grassroots work.

Furthermore, China's vocational legal education focus mainly on quality education and multi-cultivation of talent based on a variety of social resource, in purpose of the training of a group of outstanding complex and innovative law professionals. In this training process, because vocational students tend to have diversified and personalized way of thinking, and can withstand great ideological and psychological pressure, it is demanded that the teaching methods of vocational law education must be constantly innovative, advance with the times, all to the centre of the cultivation of outstanding students, truly reflect the people oriented teaching philosophy, continuously enco- urage students to develop their personality and potential, cultivate truly practical legal talents with professional capacity, able to take up the mission of the law, and able to make a significant contribution to the legal system construction of the country, in cooperation with a wide range of education models.

\section{References}

[1] Gillett J.E. Chemical Engineering Education in the next Century. Chemical Engineering \& Technology. 2001

[2] R. Polanco et al. Effects of a Problem-based Learning Program on Engineering Students" Academic Achievements in a Mexican University. Innovations in Education and Teaching International. 2004

[3] Duderstadt J. J. Engineering for a Changing World: A Roadmap to the Future of Engineering Practice, Research, and Education. 2008 